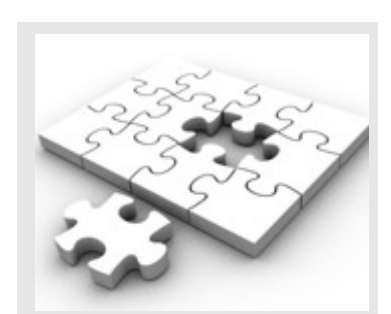

In an effort to facilitate the selection of appropriate peer reviewers for South African Journal of Physiotherapy, we ask that you take a moment to update your electronic portfolio on www.sajp.co.za for our files, allowing us better access to your areas of interest and expertise, in order to match reviewers with submitted manuscripts.

If you would like to become a reviewer, please visit the journal website and register as a reviewer.

To access your details on the website, you will need to follow these steps:

1. Log into the online journal at http://www. sajp.co.za

2. In your 'user home' [http://www.sajp.co.za/ index.php/ve/user] select 'edit my profile' under the heading 'my account' and insert all relevant details, bio statement and reviewing interest.

3. It is good practice as a reviewer to update your personal details regularly to ensure contact with you throughout your professional term as reviewer to South African Journal of Physiotherapy.

Please do not hesitate to contact us if you require assistance in performing this task.

Publisher: publishing@aosis.co.za Tel: +27 219752602

Fax: +27 219754635

\section{South African Journal of Physiotherapy}

The editorial team of South African Journal of Physiotherapy recognises the value and importance of the peer reviewer in the overall publication process - not only in shaping the individual manuscript, but also in shaping the credibility and reputation of our journal.

We are committed to the timely publication of all original, innovative contributions submitted for publication. As such, the identification and selection of reviewers who have expertise and interest in the topics appropriate to each manuscript are essential elements in ensuring a timely, productive peer review process.

We would like to take this opportunity to thank all reviewers who participated in shaping this volume of South African Journal of Physiotherapy:

Aimee V. Stewart
Anna C.M. Braga
Anthea Rhoda
Benita Olivier
Brenda Morrow
Conran Joseph
Dawn V. Ernstzen
Di Cooper
Farhana Karachi
Hellen Myezwa
Ina Diener
Jessica Stander
Joliana S. Phillips
Jose M. Frantz
Juvenal Biraguma
Kebogile E. Mokwena
Liezel Wegner

Linzette Morris

Marianne Unger

Michael Rowe

Natalie Benjamin

Nonceba Mbambo-Kekana

Nondwe B. Mlenzana

Preshani Reddy

Quinette Louw

Rene Phetlhu

Romy Parker

Seyi Amosun

Silmara Hanekom

Soraya Maart

Surona Visagie

Tania Steyl

Tania van Rooijen

Witness Mudzi

We appreciate the time taken to perform your review successfully. 